\title{
Preserving Cognition, Quality of Life, Physical Health and Functional Ability in Alzheimer's Disease: The Effect of Physical Exercise (ADEX Trial): Rationale and Design
}

\author{
Kristine Hoffmann ${ }^{a} \quad$ Kristian S. Frederiksen $^{a} \quad$ Nanna Aue Sobol $^{b}$ Nina Beyer ${ }^{b}$ \\ Asmus Vogel ${ }^{a}$ Anja Hviid Simonsen ${ }^{a}$ Peter Johannsen ${ }^{a}$ Annette Lolk ${ }^{c}$ \\ Ole Terkelsen $^{d}$ Carl W. Cotman $^{\mathrm{e}}$ Steen G. Hasselbalch ${ }^{\mathrm{a}}$ Gunhild Waldemar $^{\mathrm{a}}$ \\ a Memory Disorders Research Group, Danish Dementia Research Center, Department of Neurology, Copenhagen \\ University Hospital Rigshospitalet, ${ }^{\mathrm{b}}$ Musculoskeletal Rehabilitation Research Unit and Institute of Sports Medicine \\ Copenhagen, Copenhagen University Hospital Bispebjerg, and ' Department of Clinical Quality, Capital Region of \\ Denmark, Copenhagen, and ${ }^{\mathrm{d}}$ Dementia Clinic, Odense University Hospital, Odense, Denmark; ${ }^{\mathrm{e}}$ Institute for Memory \\ Impairments and Neurological Disorders, University of California-Irvine, Irvine, Calif., USA
}

\section{Key Words}

Alzheimer's disease $\cdot$ Clinical trial design · Cognition · Exercise $\cdot$ Intervention $\cdot$ Health-related quality of life . Physical function $\cdot \beta$-Amyloid · Neuroimaging

\begin{abstract}
Background: Exercise is hypothesized to improve cognition, physical performance, functional ability and quality of life, but evidence is scarce. Previous studies were of short duration, often underpowered and involving home-based light exercise programs in patients with undefined dementia. The aim of the ADEX ('Preserving Cognition, Quality of Life, Physical Health and Functional Ability in Alzheimer's Disease: the Effect of Physical Exercise') trial is to establish whether aerobic exercise is effective in improving cognition as well as in reducing the prevalence of psychiatric symptoms among patients with Alzheimer's disease (AD). Methods: The ADEX study is a multicenter, single-blind, randomized trial with two arms: an intervention group attending 16 weeks of continuously supervised moderate-to-high intensity aerobic ex-
\end{abstract}

\section{KARGER}

E-Mail karger@karger.com

www.karger.com/ned ercise and a control group receiving usual care. We plan to recruit 192 patients with mild AD. The primary outcome measure is change from baseline in cognitive performance at 16 weeks (as measured by the Symbol Digit Modalities test). Conclusions: To our knowledge this is the first large-scale controlled study to investigate the effects of supervised moderate aerobic exercise on cognition in patients with AD. Recruitment began in January 2012 and results are expected to be available in 2014 . We summarize the methodological challenges we and other studies have faced in this type of complex multicenter intervention with unique challenges to study design. @ $2013 \mathrm{~S}$. Karger AG, Basel

\section{Introduction}

Alzheimer's disease (AD) is the most prevalent neurodegenerative disorder worldwide, affecting more than $50 \%$ of patients with dementia. The clinical hallmarks of $\mathrm{AD}$ are progressive memory impairment and decreased 
activities of daily living (ADL), ultimately leading to loss of independent living skills [1]. Current treatment for AD is symptomatic and can only temporarily slow down the progression of symptoms. New, potential disease-modifying treatment strategies have so far not demonstrated clinically relevant effects [2], underscoring the need for research in nonpharmacological treatments.

The relationship between physical activity and cognitive function is intriguing but remains undetermined [3, 4]. There are some indications that physical activity may protect against the occurrence of cognitive decline in nondemented subjects [5]. Additionally, meta-analyses of randomized clinical trials (RCTs) reported a modest effect on cognition from aerobic exercise in healthy older adults [6]. These results may, however, not be transferrable to patients with $\mathrm{AD}$.

It is encouraging that previous intervention trials have been able to improve physical function in patients with $\operatorname{AD}[7,8]$ and other cognitive disorders $[9,10]$, but they did not include cognitive measures. Furthermore, in the study by Hauer et al. [9] exercise did not include endurance training and the endurance training intensity was not specified or lower than that planned in our study $[7$, $8,10]$.

The underlying mechanisms for a potential effect of physical exercise on $\mathrm{AD}$ are unclear. According to current understanding of the pathophysiology of $\mathrm{AD}$, cortical deposition of $\beta$-amyloid $(A \beta)$ is considered central to the development of $\mathrm{AD}$. In mice models of $\mathrm{AD}$, physical exercise decreased $A \beta$ depositions in association with a positive effect on cognitive function [11, 12]. Brain-derived neurotrophic factor (BDNF) is important for long-term potentiation and formation of memory $[13,14]$. Potential neuroprotective effects of physical exercise include an increase in BDNF [15] and enhanced hippocampal neurogenesis [16]. In healthy subjects the beneficial effects of physical exercise have been supported by studies showing increased memory performance and at the same time increased whole-brain and hippocampal volumes $[17,18]$, as well as increased activity in neural networks [19]. Moreover, cross-sectional studies in $\mathrm{AD}$ suggest that cardiorespiratory fitness is positively correlated to wholebrain [20] and medial temporal lobe [21] volume. Furthermore, an observational study in $\mathrm{AD}$ patients shows that greater cardiorespiratory fitness is associated with slowed progression of clinical symptoms and brain atrophy [22].

Only few intervention studies have investigated the underlying mechanisms of a potential effect and this is mainly examined in patients with mild cognitive impairment
(MCI) [23] or subjective memory complaints [24]. Furthermore, previous investigators have called for more hypothesis-driven research on changes in biomarkers [25].

Few RCTs have investigated the potential effect of physical exercise on the progression of cognitive decline. In general, most studies are on nursing home residents with $\mathrm{AD}$ and methodological issues restrict the conclusions which may be drawn from these studies $[26,27]$. In nursing home residents with $\mathrm{AD}$ or unspecified dementia, some intervention studies show a positive effect of physical exercise on cognition $[28,29]$, whereas others show no effect [30-32]. In home-dwelling patients with $\mathrm{AD}$, cognition has been the primary outcome in only one small study [33], which showed a positive effect of lowintensity physical exercise on tests of global cognition. In patients with MCI and in older subjects with memory complaints, physical exercise interventions have shown an effect on global cognition [34] and executive function, especially in women [23].

Some of the conflicting results from previous studies may arise from difficulties in comparing studies due to variations in outcome measures and exercise modalities. Methodological issues, such as small sample sizes and unsupervised intervention programs, may contribute to the discrepancies. Further, the effect of high-intensity exercise remains unknown since most studies have used lowintensity exercise programs [25]. Only a few studies assess depressive and behavioral symptoms in home-dwelling patients with $\mathrm{AD}[33,35,36]$ and in nursing home residents $[8,37,38]$. Quality of life has only rarely been an outcome parameter [34, 35].

As a result, we are launching a large, methodologically rigorous RCT entitled, 'Preserving Cognition, Quality of Life, Physical Health and Functional Ability in Alzheimer's Disease: the Effect of Physical Exercise (ADEX)' with the aim to investigate the potential benefits of a moderate-to-high intensity aerobic exercise program on cognition, health-related quality of life, behavioral and psychological symptoms, and physical function in patients with mild AD. Further, mechanisms of the potential effects of physical exercise will be explored using fluid and imaging biomarkers. This report describes the rationale and design of the study.

\section{Methods}

\section{Design}

The ADEX study is a multicenter, single-blinded RCT with two arms - a control arm (receiving treatment as usual) and an intervention arm of 16 weeks ( $1 \mathrm{~h}, 3$ times per week) of supervised 
Table 1. ADEX inclusion and exclusion criteria

\begin{tabular}{|c|c|c|c|}
\hline \multicolumn{2}{|c|}{ Inclusion criteria } & \multicolumn{2}{|c|}{ Exclusion criteria } \\
\hline 1 & NINCDS-ADRDA and DSM-IV criteria for AD & 1 & $\begin{array}{l}\text { Participation in aerobic exercise program (moderate-to-hard } \\
\text { intensity) more than twice weekly on a regular basis }\end{array}$ \\
\hline 2 & $50-90$ years of age & 2 & $\begin{array}{l}\text { Any musculoskeletal or joint problems that could interfere } \\
\text { with completion of the study (significant joint problems, back } \\
\text { pain or pain in arms and legs that provide problems with mo- } \\
\text { bility in daily activities) }\end{array}$ \\
\hline 3 & A score $\geq 20$ on the MMSE & 3 & $\begin{array}{l}\text { Male participants with all of the following risk factors, even if } \\
\text { asymptomatic: smoking, arterial hypertension (systolic blood } \\
\text { pressure }>180) \text { and hypercholesterolemia }(>7 \mathrm{mM})\end{array}$ \\
\hline 4 & $\begin{array}{l}\text { Brain imaging (CT or MRI) consistent with a diagnosis of } \\
\mathrm{AD}\end{array}$ & 4 & $\begin{array}{l}\text { Major neurological (other than AD), cardiac or other medical } \\
\text { diseases that constitute a contraindication to physical activity, } \\
\text { i.e. severe aorta stenosis or cardiac rhythm disturbances. } \\
\text { Stent operation or previous myocardial infarction is not an } \\
\text { exclusion criteria if the participant has had a recent (within } \\
3 \text { months) normal exercise test }\end{array}$ \\
\hline 5 & $\begin{array}{l}\text { Caregiver with regular contact to the participant (more } \\
\text { than once a month) who is also willing to participate in } \\
\text { the study }\end{array}$ & 5 & Severe cerebrovascular disease judged from cranial CT or MRI \\
\hline 6 & $\begin{array}{l}\text { General good health allowing the participant to } \\
\text { participate in physical exercise }\end{array}$ & 6 & $\begin{array}{l}\text { Arterial hypertension defined as systolic blood pressure }>180 \\
\text { and diastolic }>100\end{array}$ \\
\hline 7 & At least 7 years of schooling and Danish speaking & 7 & $\begin{array}{l}\text { Severe psychiatric disease, as well as alcohol or drug abuse } \\
\text { within the last } 2 \text { years }\end{array}$ \\
\hline 8 & Visual acuity and hearing that allow cognitive testing & 8 & \multirow{2}{*}{$\begin{array}{l}\text { Daily or almost daily intake of medications with known anti- } \\
\text { cholinergic or adrenergic effect estimated to affect cognitive } \\
\text { abilities; subjects treated with tricyclic antidepressants, antipsy- } \\
\text { chotics (low doses of anxiolytics, e.g. oxazepam } 15 \mathrm{mg} / \text { day, and } \\
\text { nonbenzodiazepine hypnotics for the night are allowed) }\end{array}$} \\
\hline 9 & $\begin{array}{l}\text { At least } 3 \text { months of stable doses if the patient is receiving } \\
\text { antidementia medication or mood stabilizing medication }\end{array}$ & & \\
\hline
\end{tabular}

moderate-to-high intensity aerobic exercise. Prior to initiation of the study, as recommended in the Medical Research Council's guidelines for complex interventions [39], an uncontrolled pilot study was carried out to ensure the acceptability, safety and feasibility of the intervention and study design.

\section{Recruitment}

Based on power calculations (see below), the goal is to recruit 192 community-dwelling participants of 50-90 years of age with mild $\mathrm{AD}$ who also have a caregiver willing to participate. Table 1 presents inclusion and exclusion criteria. Participants are being recruited across 8 sites in Denmark (Copenhagen, Slagelse, Roskilde, Odense, Aalborg, Aarhus, Svendborg and Glostrup).

Initiated in January 2012, the study is scheduled to end in 2014, at which point results will be made available. While the recruitment process will be continuous throughout the study period until the target has been reached, patients are randomized every 6 months in blocks of 5-10 per participating center. Recruitment will mainly be carried out among patients being followed in participating memory clinics. Moreover, information material is being distributed to general practitioners, private practice neurolo- gists, other relevant specialists and primary care personnel. Potential participants are identified by screening patient records and checking suitability of the participants according to the inclusion and exclusion criteria. A screening log of all the patients deemed suitable for possible inclusion into the study is kept by each clinic.

\section{Information and Screening}

At the first visit, participants are given written and oral information. At the second visit (screening), after obtaining informed consent, inclusion and exclusion criteria are reviewed and thorough somatic and neurological examinations, including ECG and blood pressure measurements, are performed. A Mini Mental State Examination (MMSE) [40] is administered to ensure that participants meet the inclusion criteria with an MMSE score $>19$. No upper limit of MMSE score is applied. Demographic data and detailed medical history, including actual medication, are obtained and a diagnosis of $\mathrm{AD}$ is confirmed according to the NINDSADRDA and DSM-IV criteria.

If the participant meets the inclusion criteria, a baseline visit is planned, at which time the baseline assessments will be carried out. A letter informing the participant's general practitioner about the 
participation is sent encouraging him/her to refer the patient to the memory clinic if any study-related problems occur. Likewise, participants are encouraged to discuss any medical concerns with the research staff at their memory clinic.

\section{Randomization and Blinding}

Following baseline assessment, participants are randomly allocated to the exercise program or usual care group (control group) using a computerized random-number generator primarily in blocks of 8 ( 4 subjects randomly allocated to each group) to each participating center. If a center is unable to recruit 8 participants, a minimum of 5 participants is allowed. If a center recruits an uneven number of participants, skewed randomization is performed in favor of the intervention group. Allocation numbers are given over the phone and kept under sealed conditions by an investigator not directly involved in the project. Raters and testers are blinded to group allocation and previous test results; due to the nature of the study, however, the participants cannot be blinded. Prior to all assessments, participants are reminded not to disclose their group allocation to testers and raters.

All baseline data are collected prior to the randomization to prevent participants and staff from being biased due to group assignment.

\section{Intervention}

On the first day of the exercise program, participants and their caregivers are invited to a meeting where they are informed about the rationale for the study, the aerobic exercise program, appropriate exercise equipment (clothes and shoes), the etiology of overuse injuries and how to avoid them, how to react if exercise causes discomfort and what to do in the event of an overuse injury.

Exercise sessions are conducted in a group of 3-5 participants for $1 \mathrm{~h}, 3$ times per week for 16 weeks. The purpose of the first 4 weeks of exercise is to accustom the participants to exercising (adaptation exercise). This period focuses on strength exercises, primarily of the legs (twice weekly) and an introduction to fitness exercise (once weekly). During the next 12 weeks, all exercise sessions focus on moderate-to-high intensity aerobic exercise (in total $3 \times 10$ min on ergometer bicycle, cross trainer and treadmill). Individually tailored, the exercise is designed to achieve an intensity of $70-80 \%$ of heart rate reserve. Heart rate and perceived exertion are monitored during all exercise sessions to ensure that the participants exercise with the intended intensity. Each session is supervised by the same experienced physiotherapist (who is different from the blinded tester performing the tests at baseline and at 4, 16 and 20 weeks).

Records of adherence to the program (attended sessions) are kept for each exercise session. Participants are not excluded due to adherence or compliance problems. Transportation to and from exercise sessions is reimbursed based on need in an effort to remove any barriers preventing participants and their caregivers from enrolling.

\section{Control Group}

The control group receives usual care for the first 16 weeks, followed by 4 weeks of supervised adaptation exercise for 1 h, 3 times per week. As for the intervention group, the first training session consists of an information meeting. The adaption exercise is also offered to the control group to strengthen recruitment and adherence to the program.

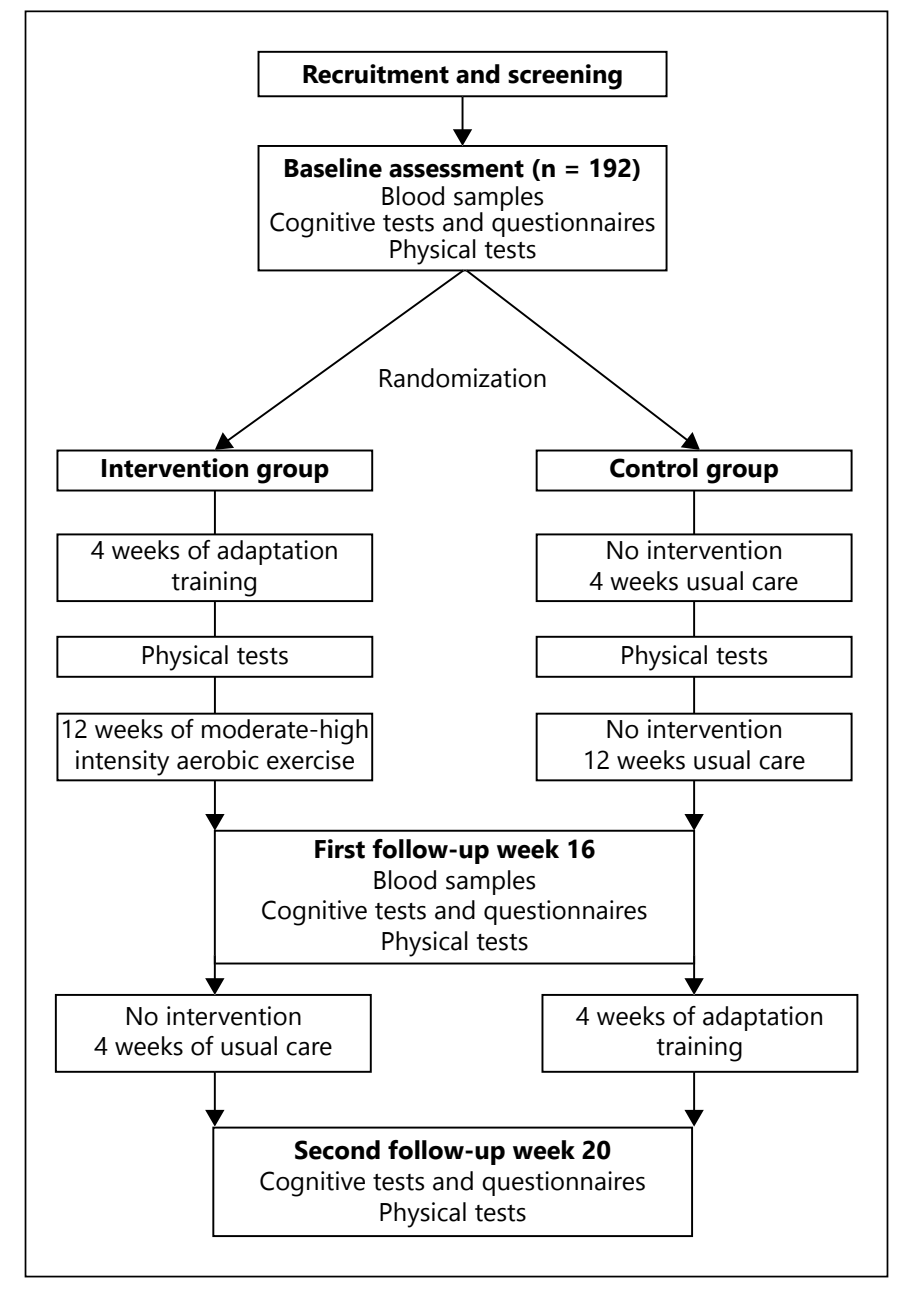

Fig. 1. Flowchart of the ADEX study. The estimated total number of participants is 192 .

Usual care comprises planned outpatient visits (usually every 6 months) and access to memory clinic staff if medical or other needs necessitate contact. Moreover, participants are encouraged not to discontinue any participation in social or other activities.

\section{Clinical Assessment Visits}

The clinical assessments are comprised of two components: (1) cognitive/behavioral assessments lasting $1.5 \mathrm{~h}$ and (2) physical testing lasting $1 \mathrm{~h}$. Participants are assessed at baseline, after 16 weeks (first follow-up) and after 20 weeks (second follow-up). In addition, physical performance is evaluated after 4 weeks of adaptation exercise (fig. 1). All assessment visits must be performed within 10 days before the first day of the intervention.

\section{Cognitive Measures}

The Symbol Digit Modalities test (SDMT) [41] is a simple substitution task using a reference key with nine different pairs of numbers and geometric figures that the participant must pair in a given time interval. Two scores are obtained in this study: (1) the number 
of correct responses within the 90 -second response time and (b) the number of correct responses within a 120-second response time.

The MMSE [40] is used as a screening instrument for global cognitive function. In the Alzheimer's Disease Assessment Scale Cognitive Section (ADAS-Cog) recall test [42], the participant reads a list of 10 words and is asked to recall as many words as possible directly thereafter. The procedure is repeated 3 times. An immediate recall score (total number of correct words recalled on the 3 trials) and a delayed recall score (number of correct words recalled after $10 \mathrm{~min}$ ) are recorded. Verbal fluency is evaluated based on two parts, category and lexical fluency. To assess category fluency, the category 'animals' is used. The score for this test is based on the number of different animals provided in $1 \mathrm{~min}$. Lexical fluency is assessed with the letters F, A and S. For each letter, there is a 1-min response time. A total lexical score is the sum of the scores obtained on the 3 subtests. The Stroop Color and Word test [43] consists of three different parts (three different pages, each with 100 items). For each part, there is a 45 -second time limit. Participants are asked to read the items as quickly as possible and then stopped if they make any errors. On the word page, the words 'green', 'red' and 'blue' are printed in black ink. The color page consists of 100 items all written as XXX and printed in red, green or blue. On the color word page, the names of the colors are printed in a different color than that which the word spells, i.e. the color and the word do not match. Each page is preceded by a reminder on what to do to minimize memory load. The score for each part is the number of words the participant can read in $45 \mathrm{~s}$.

\section{Questionnaires}

The Neuropsychiatric Inventory (NPI) [44] is a well-established assessment of 12 different behavioral and psychological symptoms common in $\mathrm{AD}$. The caregiver rates each symptom according to the frequency and severity. The Danish validated version is used [45]. The score (frequency times severity) for all items in total, as well as subitems (depression, anxiety, aggression, irritability and apathy) will be used.

The Alzheimer's Disease Cooperative Study - Activities of Daily Living (ADCS-ADL) scale [46] uncovers 23 ADL items by interviewing the caregiver. It includes more complex ADL for the assessment of mild $\mathrm{AD}$ such as reading books or magazines, leisure activities and household chores. The severity of any depressive symptoms is rated using the Hamilton Depression Rating Scale 17 items (HAMD-17) [47] by interviewing the participant. Higher scores indicate more severe symptoms.

Two questionnaires are administered to both participant and caregiver, the EuroQol-5D-5L (EQ-5D), including EuroQol Visual Analogue Scale (EQ-VAS) scale [48] and Physical Activity Scale for the Elderly (PASE) [49]. The EQ-5D and EQ-VAS are employed for measuring health-related quality of life. They consist of a weighted sum of five dimensions: mobility, self-care, usual activities, pain/discomfort and anxiety/depression, which provides a simple descriptive profile and a single index value for health status (VAS score).

PASE is administered by interview at baseline to assess the selfreported level of physical activity (household and leisure activities) of the participant prior to the baseline tests. Both participant and caregiver are interviewed.

Furthermore, exercise self-efficacy is assessed with the Exercise Self-Efficacy Scale by asking participants how confident they are about exercising under certain adverse conditions [50].
The research staff performing the cognitive tests and questionnaires (raters) are blinded to group assignment and their only role in the study is to perform assessment before and after exercise.

To ensure uniformity of the cognitive and questionnaires assessment, all raters have to complete a 1-day course led by an experienced neuropsychologist and an experienced psychiatrist. Training of the raters is repeated annually to standardize the assessment.

\section{Physical Measures}

All participants perform the following physical tests at baseline and at 4, 16 and 20 weeks (fig. 1). The 6-min Astrand Cycle Ergometer test (Monark Ergomedic 839E; Monark Exercise AB, Sweden) estimates the maximal oxygen uptake based on age, body weight and the workload, and average heart rate during the last minute of the test [51]. Functional performance tests include the Timed Up and Go (TUG) test [52], the 30-second chair stand test (the number of full stands in $30 \mathrm{~s}$ with arms folded across the chest from a standard chair) [32], the timed 10-min walk test (usual speed) [53] and the timed 400-meter walk test (fast speed) [54]. In addition, dual task performance is measured with the timed 10-min walk test combined with naming the months backwards and counting backwards from 50, respectively [53].

A subgroup of subjects perform additional tests at baseline and at 16 and 20 weeks to assess the following: (1) motor learning using the Rotary Pursuit test (Photoelectric Rotary Pursuit Model 30014C; Lafayette Instrument Europe, UK) [55]; (2) handgrip strength in each hand using a Jamar ${ }^{\circledR}$ dynamometer (Lafayette Instrument Europe) [56]; (3) maximal isometric knee extension strength at an angle of $90^{\circ}$ of knee flexion $\left(0^{\circ}=\right.$ full extension $)$ using a handheld dynamometer (Lafayette Manual Muscle Testing System, Model 01165; Lafayette Instrument Europe) [57], and (4) maximal single leg extensor power using a Nottingham Leg Extensor Power Rig ${ }^{\circledR}$ (Medical Engineering Unit, Queen's Medical Centre, Nottingham University, UK) [58]. A graded cycle ergometer exercise test with simultaneous recording of the ECG is carried out to determine maximal oxygen uptake $\left(\mathrm{VO}_{2}\right.$ peak) using a pedaling frequency of 60 RPM on the Monark cycle ergometer and incrementally increasing load to exhaustion. The test is performed with a mask for measurement of maximal oxygen uptake by indirect calorimetry. Expired gases are collected online and analyzed with a metabolic measurement system (Jaeger, Master Screen CPX vers.5.21, Cardinal Health, Germany). A respiratory exchange ratio $>1.10$ indicates a valid test [59].

The research staff performing the physical tests (testers) attend a 1-day course on standardization of the physical tests led by an exercise physiologist and the principal physiotherapist investigator. In addition, they receive an instructional video of the tests and a visit by the principal physiotherapist investigator to ensure good quality of test procedures at each of the sites. The physiotherapists who deliver the exercise intervention (trainers) attend a 2-day course on the exercise program led by an exercise physiologist and the principal physiotherapist investigator. They are also visited by the principal physiotherapist investigator to ensure that the exercises are performed at each of the sites according to the protocol. The intervention is documented and standardized but individually tailored to each participant. New testers and trainers enrolled during the study will attend an individualized course led by the principal physiotherapist investigator. 
Blood Samples, Cerebrospinal Fluid and Imaging

A panel of fluid biomarkers is measured to monitor the effects of physical exercise on pathology associated with AD. Blood samples (whole blood, plasma and serum) are collected from all participants at baseline and at first follow-up and stored in a central biobank.

A subgroup (up to 48 participants) will undergo magnetic resonance imaging (MRI), lumbar puncture and $\mathrm{A} \beta$-PET $\left({ }^{11} \mathrm{C}-\mathrm{PiB}-\right.$ PET) at baseline and first follow-up. This subgroup also has to perform the additional physical tests at baseline and at 16 weeks as described above. Lumbar puncture is performed at the screening visit and MRI/PET is done within 2 months of the start and at the end of the 16-week intervention. Biomarkers specific to pathology in $\mathrm{AD}$ ( $\mathrm{A} \beta$ in cerebrospinal fluid, $\mathrm{CSF}$, and plasma, phospho-tau and neprilysin in CSF) as well as biomarkers of downstream processes such as neural degeneration (CSF-tau) are analyzed. Moreover, to further elucidate the underlying mechanisms that may mediate a beneficial effect of physical exercise on $\mathrm{AD}$, BDNF, markers of insulin and glucose metabolism (glycosylated hemoglobin, HbA1C), inflammation (IL-1 and IL-6, and TNFa), hormones, cholesterol and triglycerides are measured in the blood.

\section{Outcome Measurements}

The primary outcome measure is change from baseline at 16 weeks in the SDMT score (120 s). The following tests (all change from baseline to week 16) are secondary cognitive outcome measures: ADAS-Cog recall test, verbal fluency, Stroop Color and Word test and MMSE. Additional secondary measures include changes in physical parameters, patient-reported health-related quality of life (EQ-5D and EQ-VAS), ADL (ADCS-ADL) and behavioral and depressive symptoms (table 2).

\section{Adverse Event Reporting}

Adverse events are recorded in the case report form. The protocol distinguishes between adverse events that may be directly attributable to the study interventions and the monitoring of adverse events not attributable to the study. Serious adverse events are reported within $24 \mathrm{~h}$ to the principal investigator. An independent safety committee consisting of a cardiologist and an orthopedic surgeon surveys the study, evaluates serious adverse events and performs a midterm interim analysis of adverse effects to evaluate safety issues that may warrant termination of the study. Medications and changes in medications during the study period are also registered.

\section{Surveillance and Monitoring}

Data monitoring is done according to the Medical Research Council [39] guidelines. Data from all centers are collected and monitored continuously by an investigator not directly involved in the project and blinded to the allocation group. The monitor also visits all centers annually.

\section{Health Economic Analysis}

Costs related to the intervention are calculated based on the expenses associated with exercise instruction and support, the time spent by participants and relatives, transportation costs and the participants' use of health care services. Cost-effectiveness (cost per quality-adjusted life year) is estimated from these cost calculations combined with changes in EQ-5D-5L scores over time during the observation period. Costs involved in the use of health care services by participants and relatives are estimated from national administrative health registries.

\section{Sample Size}

Primary and secondary outcome changes from baseline at 16 weeks will be analyzed in the intent-to-treat population as well as in the per-protocol population. Based on the SDMT data from a previous study of aerobic exercise in patients with MCI [23], 154 subjects must be included $(\alpha=5 \%, \beta=20 \%)$ to identify a minimal clinically relevant difference (minimal relevant difference, MIREDIF) set at 5 points on the SDMT (typical mean values in mild AD: 50-60). With 192 subjects (24 per center on average), the present study will be able to demonstrate or reject a clinically meaningful effect on the primary endpoint if a dropout rate of $20 \%$ is assumed.

This sample size also makes it possible to detect clinically relevant differences in some important secondary outcomes: 126 subjects must be included ( $\alpha=\%, \beta=20 \%)$ to identify an MIREDIF set to 6 points (equals $10 \%$ ) in the EQ-5D-5L index score completed by caregivers (typical average values in mild AD: $60-70$ ) [60]. Further, 50 subjects must be included $(\alpha=5 \%, \beta=20 \%)$ to find an MIREDIF of $5 \mathrm{ml} /(\mathrm{kg} \cdot \mathrm{min}$; equals $15 \%)$ in the $\mathrm{VO}_{2} \max$ measured with the Astrand cycle ergometer test [61].

Data analysis will be corrected for multiple testing when necessary.

\section{Ethics}

The study is approved by the Danish National Committee on Biomedical Research Ethics, reference number H-3-2011-128 and by the Danish Data Protection Agency (J No. 30-0718). Even though exercise has not been established to be effective in the treatment of $\mathrm{AD}$, its association with general health benefits is well accepted. As the duration and intensity of the exercise needed for a clinical effect is unknown, we find it ethically acceptable to offer all participants the opportunity to participate in an exercise program for either 4 or 16 weeks. Previous exercise intervention studies in patients with cognitive dysfunction and with similar exercise intensity as in our study report a very low incidence of adverse events [23,34]. Therefore, we consider the potential benefits of the intervention to outweigh the risks associated with participation in our study.

\section{Discussion}

To our knowledge, this is the first large-scale RCT to investigate physical and cognitive effects of continuously supervised moderate-to-high intensity aerobic exercise in home-dwelling patients with an established diagnosis of mild AD. Depending on the results, this study could stimulate the development of community-deliverable moderate-to-high intensity aerobic exercise programs accessible for all patients with mild AD. The ADEX study is designed to overcome some of the methodological and design-related problems seen in previous studies. Because complex interventions of this kind present unique 
Table 2. Outline of the assessments and timelines of the ADEX study

Screening Baseline Physical test First follow-up Second follow-up (0 weeks) (4 weeks) (16 weeks) (20 weeks)

\section{Assessment tools}

Demographics, medical history and medication

Blood samples

$\begin{array}{lll}\mathrm{X} & \mathrm{X} & \mathrm{X} \\ \mathrm{X} & \mathrm{X} & \end{array}$

Cognitive tests
SDMT
MMSE
ADAS-Cog recall test
Verbal fluency test (category and lexical)
Stroop Color and Word test
Questionnaires
EQ-5D and EQ-VAS
Hamilton Depression Rating Scale 17 items (HAMD-17)
PASE
Caregiver-rated questionnaires
ADCS-ADL scale
NPI
EQ-5D and EQ-VAS
PASE

Physical tests and questionnaires

Height, weight
Exercise Self-Efficacy Scale (questionnaire)

Astrand Cycle Ergometer test for estimating $\mathrm{VO}_{2} \max$

TUG test

Timed10-meter walk test

Timed 10-meter dual-task test

Timed 400-meter fast walking test

30-second chair stand test

\begin{tabular}{lll}
$\mathrm{X}$ & $\mathrm{X}$ & $\mathrm{X}$ \\
$\mathrm{X}$ & $\mathrm{X}$ & $\mathrm{X}$ \\
$\mathrm{X}$ & $\mathrm{X}$ & $\mathrm{X}$ \\
$\mathrm{X}$ & $\mathrm{X}$ & $\mathrm{X}$ \\
$\mathrm{X}$ & $\mathrm{X}$ & $\mathrm{X}$ \\
\hline
\end{tabular}

Assessment tools for subgroup

Imaging and biomarkers

$\begin{array}{lll}\text { MRI } & \mathrm{X} & \mathrm{X} \\ \mathrm{A} \beta \text {-PET }\left({ }^{11} \mathrm{C}-\mathrm{PiB}-\mathrm{PET}\right) & \mathrm{X} & \mathrm{X} \\ \mathrm{CSF} & \mathrm{X} & \mathrm{X}\end{array}$

Supplementary physical tests

Motor learning (rotary pursuit)

Handgrip strength

Maximal isometric knee extension strength

Maximal single-leg extensor power

Maximal oxygen uptake $\left(\mathrm{VO}_{2}\right.$ peak)

$\begin{array}{lll}\mathrm{X} & \mathrm{X} & \mathrm{X} \\ \mathrm{X} & \mathrm{X} & \mathrm{X} \\ \mathrm{X} & \mathrm{X} & \mathrm{X}\end{array}$

$\begin{array}{lll}X & X & X \\ X & X & X\end{array}$

$\mathrm{X}$

$\begin{array}{llll}\mathrm{X} & \mathrm{X} & \mathrm{X} & \mathrm{X} \\ \mathrm{X} & \mathrm{X} & \mathrm{X} & \mathrm{X} \\ \mathrm{X} & \mathrm{X} & \mathrm{X} & \mathrm{X} \\ \mathrm{X} & \mathrm{X} & \mathrm{X} & \mathrm{X} \\ \mathrm{X} & \mathrm{X} & \mathrm{X} & \mathrm{X} \\ \mathrm{X} & \mathrm{X} & \mathrm{X} & \mathrm{X} \\ \mathrm{X} & \mathrm{X} & \mathrm{X} & \mathrm{X} \\ \mathrm{X} & \mathrm{X} & \mathrm{X} & \mathrm{X}\end{array}$

For a more detailed description of the tests, see the following sections in the main body of text: Cognitive Measures, Questionnaires and Physical Measures.

${ }^{1}$ Primary outcome.

challenges to study design, piloting was undertaken to optimize the exercise program. In the pilot study, which comprised just 2 weeks of adaptation exercise, patients and caregivers reported that the subsequent first couple of weeks of the aerobic exercise were too challenging. As a result, the design has been adapted to include 4 weeks of adaptation. No serious adverse events related to the exercise were experienced during the pilot study. Moderate-to-high intensity aerobic exercise was selected since previous studies in healthy older adults show that aerobic 
exercise clearly benefits cognition (spatial memory) and hippocampal volume compared to resistance exercise [17]. Whether these findings in healthy subjects are transferrable to home-dwelling patients with $\mathrm{AD}$ is uncertain.

Since low sample size and high dropout rates contribute to insufficient power in many other RCTs [26], one of our primary priorities is to promote recruitment and adherence. Chosen due to practical considerations, group exercise is the most cost-effective way to implement supervised exercise, but we also believe that the social interaction has a positive effect on adherence and participation. Other approaches involve reimbursement of transportation and a 4-week adaptation exercise period for the control group after the assessment of the outcome measures. Supervised individually, tailored aerobic exercise provides benefits in terms of objectivity and flexibility, since the individual intensity can be assessed in data analyses. This also means that participants need not be excluded unless participation and intensity drops to negligible levels.

Selection bias means that it is only possible to investigate the effect of moderate-to-high intensity aerobic exercise in a selected population of patients with AD. In essence this means that our study is an efficacy study rather than an effectiveness study. A logbook of participants not meeting inclusion criteria or not willing to participate will be kept to help identify the characteristics of patients who may benefit more from a different type of exercise intervention and to support future implementation in a broader group of patients with $\mathrm{AD}$. However, to investigate the potential effect of exercise on $\mathrm{AD}$, examining a well-defined homogenous group of patients is necessary. Clustering effects cannot be ruled out in a design involving 8 different memory clinics and 8 different exercise facilities with different staff. To minimize clustering effects, all raters, trainers and testers undergo regular and extensive training in standardized procedures throughout the study period. Although estimating clustering effects a priori is possible, as is adjusting sample size calculation accordingly, we have chosen not to do so since reliable estimates were not available. However, post hoc analysis to test for clustering effects will be performed and taken into consideration in the statistical analyses if such an approach is deemed appropriate.

In order to explore the underlying pathophysiology of a potential effect of physical exercise in $\mathrm{AD}$, biomarkers are collected in a subgroup of participants. A limitation of the substudy on CSF and PET A $\beta$ biomarkers is the duration of the exercise program. Recently, anti- $\mathrm{A} \beta$ monoclonal antibody treatment was shown to reduce cortical ${ }^{11} \mathrm{C}$ -
$\mathrm{PiB}$ retention over 78 weeks [62], which means the time window in our study may be too short to show an effect on $\mathrm{AD}$ pathology. Extending the exercise program beyond 16 weeks, however, was not considered feasible.

In summary, this rigorously conducted RCT will contribute to evidence regarding the potential effects of a supervised program of physical exercise for home-dwelling patients with $\mathrm{AD}$. If the current exercise protocol should prove to be successful, exercise could compliment medical treatment.

\section{Acknowledgments}

The ADEX study is supported by the Danish Council for Strategic Research (J No. 10-092814). The Danish Dementia Research Centre is supported by grants from the Danish Ministry of Health (J No. 2007-12143-112, project 59506/J No. 0901110, project 34501) and the Danish Health Foundation (J No. 2007B004). The ADEX trial is a multicenter study with eight participating sites in Denmark. Professor, DMSc, MD Gunhild Waldemar and Professor, DMSc, MD Steen Hasselbalch, Danish Dementia Research Center, Department of Neurology, Copenhagen University Hospital, Rigshospitalet, Denmark, are the ADEX study program director, and the national principal investigator, respectively, and Assoc. Professor Nina Beyer, Musculoskeletal Rehabilitation Research Unit and Institute of Sports Medicine Copenhagen, Copenhagen University Hospital, Bispebjerg, Denmark is the project director of physical exercise.

We wish to thank all the memory clinic investigators by site as follows:

\author{
Memory Clinic, Copenhagen University Hospital, \\ Rigshospitalet \\ Birgitte Bo Andersen, DMSc, MD
}

Regional Dementia Research Center, Copenhagen University Hospital, Roskilde

Peter Høgh, PhD, MD

Memory Clinic, Aalborg University Hospital

Karsten Vestergaard, MD

Memory Clinic, Aarhus University Hospital

Hans Brændgaard, MD

Hanne Gottrup, PhD, MD

Dementia Clinic, Odense University Hospital

Anette Lolk, Assoc. Professor, PhD, MD

Lene Wermuth, MD

Department of Geriatrics, OUH, Svendborg Hospital

Søren Jakobsen, MD

Department of Geriatrics, Slagelse Hospital

Lars P. Laugesen, MD

Robert Graff Gergelyffy, MD 
Memory Clinic, Glostrup University Hospital

Eva Bjerregaard, MD

We are grateful to all physiotherapists, study nurses and clinical raters for their contributions to the study.

\section{Disclosure Statement}

The authors have no conflicts of interest to report.

\section{References}

1 McKhann G, Drachman D, Folstein M, Katzman R, Price D, Stadlan EM: Clinical diagnosis of Alzheimer's disease: report of the NINCDS-ADRDA Work Group under the auspices of Department of Health and $\mathrm{Hu}-$ man Services Task Force on Alzheimer's Disease. Neurology 1984;34:939-944.

$>2$ Castellani RJ, Perry G: Pathogenesis and disease-modifying therapy in Alzheimer's disease: the flat line of progress. Arch Med Res 2012;43:694-698.

$>3$ Floel A, Witte AV, Lohmann H, Wersching $\mathrm{H}$, Ringelstein EB, Berger $\mathrm{K}$, et al: Lifestyle and memory in the elderly. Neuroepidemiology 2008;31:39-47.

$>4$ Auyeung TW, Kwok T, Lee J, Leung PC, Leung J, Woo J: Functional decline in cognitive impairment - the relationship between physical and cognitive function. Neuroepidemiology 2008;31:167-173.

$\checkmark 5$ Sofi F, Valecchi D, Bacci D, Abbate R, Gensini GF, Casini A, et al: Physical activity and risk of cognitive decline: a meta-analysis of prospective studies. J Intern Med 2011;269: 107-117.

-6 Angevaren M, Aufdemkampe G, Verhaar HJ, Aleman A, Vanhees L: Physical activity and enhanced fitness to improve cognitive function in older people without known cognitive impairment. Cochrane Database Syst Rev 2008:CD005381.

7 Pitkala KH, Poysti MM, Laakkonen ML, Tilvis RS, Savikko N, Kautiainen H, et al: Effects of the Finnish Alzheimer Disease Exercise Trial (FINALEX): a randomized controlled trial. JAMA Intern Med 2013;173:894-901.

$>8$ Teri L, Gibbons LE, McCurry SM, Logsdon RG, Buchner DM, Barlow WE, et al: Exercise plus behavioral management in patients with Alzheimer disease: a randomized controlled trial. JAMA 2003;290:2015-2022.

$\checkmark 9$ Hauer K, Schwenk M, Zieschang T, Essig M, Becker C, Oster P: Physical training improves motor performance in people with dementia: a randomized controlled trial. J Am Geriatr Soc 2012;60:8-15.

$>10$ Shaw FE, Bond J, Richardson DA, Dawson P, Steen IN, McKeith IG, et al: Multifactorial intervention after a fall in older people with cognitive impairment and dementia presenting to the accident and emergency department: randomised controlled trial. BMJ 2003;326:73.

11 Adlard PA, Perreau VM, Pop V, Cotman CW: Voluntary exercise decreases amyloid load in a transgenic model of Alzheimer's disease. J Neurosci 2005;25:4217-4221.
Um HS, Kang EB, Koo JH, Kim HT, Jin L, Kim EJ, et al: Treadmill exercise represses neuronal cell death in an aged transgenic mouse model of Alzheimer's disease. Neurosci Res 2011;69:161-173.

13 Korte M, Carroll P, Wolf E, Brem G, Thoenen $\mathrm{H}$, Bonhoeffer T: Hippocampal long-term potentiation is impaired in mice lacking brainderived neurotrophic factor. Proc Natl Acad Sci USA 1995;92:8856-8860.

14 Mu JS, Li WP, Yao ZB, Zhou XF: Deprivation of endogenous brain-derived neurotrophic factor results in impairment of spatial learning and memory in adult rats. Brain Res 1999; 835:259-265.

15 Nichol K, Deeny SP, Seif J, Camaclang K, Cotman CW: Exercise improves cognition and hippocampal plasticity in APOE $\varepsilon 4$ mice. Alzheimers Dement 2009;5:287-294.

16 van PH, Shubert T, Zhao C, Gage FH: Exercise enhances learning and hippocampal neurogenesis in aged mice. J Neurosci 2005;25: 8680-8685.

17 Erickson KI, Voss MW, Prakash RS, Basak C, Szabo A, Chaddock L, et al: Exercise training increases size of hippocampus and improves memory. Proc Natl Acad Sci USA 2011;108: 3017-3022.

18 Colcombe SJ, Erickson KI, Scalf PE, Kim JS, Prakash R, McAuley E, et al: Aerobic exercise training increases brain volume in aging humans. J Gerontol A Biol Sci Med Sci 2006;61: 1166-1170.

19 Colcombe SJ, Kramer AF, Erickson KI, Scalf P, McAuley E, Cohen NJ, et al: Cardiovascular fitness, cortical plasticity, and aging. Proc Natl Acad Sci USA 2004;101:3316-3321.

20 Burns JM, Cronk BB, Anderson HS, Donnelly JE, Thomas GP, Harsha A, et al: Cardiorespiratory fitness and brain atrophy in early Alzheimer disease. Neurology 2008;71:210-216.

21 Honea RA, Thomas GP, Harsha A, Anderson HS, Donnelly JE, Brooks WM, et al: Cardiorespiratory fitness and preserved medial temporal lobe volume in Alzheimer disease. Alzheimer Dis Assoc Disord 2009;23:188-197.

22 Vidoni ED, Honea RA, Billinger SA, Swerdlow RH, Burns JM: Cardiorespiratory fitness is associated with atrophy in Alzheimer's and aging over 2 years. Neurobiol Aging 2012;33: 1624-1632.

23 Baker LD, Frank LL, Foster-Schubert K, Green PS, Wilkinson CW, McTiernan A, et al: Effects of aerobic exercise on mild cognitive impairment: a controlled trial. Arch Neurol 2010;67:71-79.
24 Nagamatsu LS, Handy TC, Hsu CL, Voss M, Liu-Ambrose T: Resistance training promotes cognitive and functional brain plasticity in seniors with probable mild cognitive impairment. Arch Intern Med 2012;172:666-668.

25 Lautenschlager NT, Cox K, Cyarto EV: The influence of exercise on brain aging and dementia. Biochim Biophys Acta 2012;1822: 474-481.

26 Forbes D, Forbes S, Morgan DG, Markle-Reid M, Wood J, Culum I: Physical activity programs for persons with dementia. Cochrane Database Syst Rev 2008:CD006489.

27 Littbrand H, Stenvall M, Rosendahl E: Applicability and effects of physical exercise on physical and cognitive functions and activities of daily living among people with dementia: a systematic review. Am J Phys Med Rehabil 2011;90:495-518.

28 Kemoun G, Thibaud M, Roumagne N, Carette P, Albinet C, Toussaint L, et al: Effects of a physical training programme on cognitive function and walking efficiency in elderly persons with dementia. Dement Geriatr Cogn Disord 2010;29:109-114.

29 Stevens J, Killeen M: A randomised controlled trial testing the impact of exercise on cognitive symptoms and disability of residents with dementia. Contemp Nurse 2006;21:32-40.

30 Roach KE, Tappen RM, Kirk-Sanchez N, Williams CL, Loewenstein D: A randomized controlled trial of an activity specific exercise program for individuals with Alzheimer disease in long-term care settings. J Geriatr Phys Ther 2011;34:50-56.

31 Venturelli M, Scarsini R, Schena F: Six-month walking program changes cognitive and ADL performance in patients with Alzheimer. Am J Alzheimers Dis Other Demen 2011;26:381388.

32 Eggermont LH, Gavett BE, Volkers KM, Blankevoort CG, Scherder EJ, Jefferson AL, et al: Lower-extremity function in cognitively healthy aging, mild cognitive impairment, and Alzheimer's disease. Arch Phys Med Rehabil 2010;91:584-588.

33 Vreugdenhil A, Cannell J, Davies A, Razay G: A community-based exercise programme to improve functional ability in people with $\mathrm{Al}$ zheimer's disease: a randomized controlled trial. Scand J Caring Sci 2012;26:12-19.

34 Lautenschlager NT, Cox KL, Flicker L, Foster JK, van Bockxmeer FM, Xiao J, et al: Effect of physical activity on cognitive function in older adults at risk for Alzheimer disease: a randomized trial. JAMA 2008;300:1027-1037. 
- 35 Steinberg M, Leoutsakos JM, Podewils LJ, Lyketsos CG: Evaluation of a home-based exercise program in the treatment of Alzheimer's disease: the Maximizing Independence in Dementia (MIND) study. Int J Geriatr Psychiatry 2009;24:680-685.

-36 Nascimento CM, Teixeira CV, Gobbi LT, Gobbi S, Stella F: A controlled clinical trial on the effects of exercise on neuropsychiatric disorders and instrumental activities in women with Alzheimer's disease. Rev Bras Fisioter 2012;16:197-204.

37 Williams CL, Tappen RM: Exercise training for depressed older adults with Alzheimer's disease. Aging Ment Health 2008;12:72-80.

- 38 Rolland Y, Pillard F, Klapouszczak A, Reynish E, Thomas D, Andrieu S, et al: Exercise program for nursing home residents with $\mathrm{Al}$ zheimer's disease: a 1-year randomized, controlled trial. J Am Geriatr Soc 2007; 55:158 165.

-39 Craig P, Dieppe P, Macintyre S, Michie S, Nazareth I, Petticrew M: Developing and evaluating complex interventions: the new Medical Research Council guidance. BMJ 2008;337:a1655.

40 Folstein MF, Folstein SE, McHugh PR: 'Minimental state'. A practical method for grading the cognitive state of patients for the clinician. J Psychiatr Res 1975;12:189-198.

41 Smith A:SymbolDigit Modalities Test (SDMT) Manual, revised. Los Angeles, Western Psychological Services, 1982.

-42 Rosen WG, Mohs RC, Davis KL: A new rating scale for Alzheimer's disease. Am J Psychiatry 1984;141:1356-1364.

43 Golden C: Stroop Color and Word Test Manual. Chicago, Stoelting, 1978.

44 Cummings JL, Mega M, Gray K, RosenbergThompson S, Carusi DA, Gornbein J: The Neuropsychiatric Inventory: comprehensive assessment of psychopathology in dementia. Neurology 1994;44:2308-2314.
45 Korner A, Lauritzen L, Lolk A, Abelskov K, Christensen P, Nilsson FM: The Neuropsychiatric Inventory - NPI. Validation of the Danish version. Nord J Psychiatry 2008;62:481-485.

46 Galasko D, Bennett D, Sano M, Ernesto C, Thomas R, Grundman M, et al: An inventory to assess activities of daily living for clinical trials in Alzheimer's disease. The Alzheimer's Disease Cooperative Study. Alzheimer Dis Assoc Disord 1997;11(suppl 2):S33-S39.

47 Hamilton M: A rating scale for depression. J Neurol Neurosurg Psychiatry 1960;23:56-62.

48 The EuroQol Group: EuroQol - a new facility for the measurement of health-related quality of life. Health Policy 1990;16:199-208.

49 Washburn RA, Smith KW, Jette AM, Janney CA: The Physical Activity Scale for the Elderly (PASE): development and evaluation. J Clin Epidemiol 1993;46:153-162.

50 Marcus BH, Selby VC, Niaura RS, Rossi JS: Self-efficacy and the stages of exercise behavior change. Res Q Exerc Sport 1992;63:60-66.

51 Cink RE, Thomas TR: Validity of the Astrand-Ryhming nomogram for predicting maximal oxygen intake. Br J Sports Med 1981; 15:182-185.

52 McGough EL, Kelly VE, Logsdon RG, McCurry SM, Cochrane BB, Engel JM, et al: Associations between physical performance and executive function in older adults with mild cognitive impairment: gait speed and the Timed 'Up \& Go' test. Phys Ther 2011;91:1198-1207.

53 Schwenk M, Zieschang T, Oster P, Hauer K: Dual-task performances can be improved in patients with dementia: a randomized controlled trial. Neurology 2010;74:1961-1968.

54 Rolland YM, Cesari M, Miller ME, Penninx BW, Atkinson HH, Pahor M: Reliability of the 400-m usual-pace walk test as an assessment of mobility limitation in older adults. J Am Geriatr Soc 2004;52:972-976.
55 van Halteren-van Tilborg IA, Scherder EJ, Hulstijn W: Motor-skill learning in Alzheimer's disease: a review with an eye to the clinical practice. Neuropsychol Rev 2007;17:203212.

56 Aadahl M, Beyer N, Linneberg A, Thuesen $\mathrm{BH}$, Jorgensen T: Grip strength and lower limb extension power in nineteen 72 -year-old Danish men and women: the Health 2006 study. BMJ Open 2011;1:e000192.

57 Scherder EJ, Eggermont LH, Geuze RH, Vis J, Verkerke GJ: Quadriceps strength and executive functions in older women. Am J Phys Med Rehabil 2010;89:458-463.

58 Bassey EJ, Short AH: A new method for measuring power output in a single leg extension: feasibility, reliability and validity. Eur J Appl Physiol Occup Physiol 1990;60:385-390.

59 Wisloff U, Stoylen A, Loennechen JP, Bruvold M, Rognmo O, Haram PM, et al: Superior cardiovascular effect of aerobic interval training versus moderate continuous training in heart failure patients: a randomized study. Circulation 2007;115:3086-3094.

60 Vogel A, Bhattacharya S, Waldorff FB, Waldemar G: Proxy-rated quality of life in Alzheimer's disease: a three-year longitudinal study. Int Psychogeriatr 2012;24:82-89.

61 Thorsen L, Skovlund E, Stromme SB, Hornslien K, Dahl AA, Fossa SD: Effectiveness of physical activity on cardiorespiratory fitness and health-related quality of life in young and middle-aged cancer patients shortly after chemotherapy. J Clin Oncol 2005;23:23782388.

62 Rinne JO, Brooks DJ, Rossor MN, Fox NC, Bullock R, Klunk WE, et al: 11C-PiB PET assessment of change in fibrillar amyloid- $\beta$ load in patients with Alzheimer's disease treated with bapineuzumab: a phase-2, double-blind, placebo-controlled, ascending-dose study. Lancet Neurol 2010;9:363-372. 